\title{
Penerapan Audit Syariah Dalam Peningkatan Akuntabilitas Pengelolaan Dana Zakat, Infaq Dan Sedekah Pada Badan Amil Zakat Nasional Kabupaten Tulungagung
}

\section{Implementation Of Sharia Audit In Increasing Accountability Of Zakat, Infaq And Alms Fund AtThe National Zakat Charity Agency In Tulungagung District}

Ridwana Rochmantika, Dyah Pravitasari

Akuntansi Syariah, Fakultas Ekonomi dan Bisnis Islam

Universitas Islam Negeri Sayyid Ali Rahmatullah Tulungagung wanamantika93@gmail.com, dyahpravitasari@iain-tulungagung.ac.id

Manuscript received 13 September 2021, processed 15 September 2021, published 31 Desember

Abstact: Zakat is one of the five pillars of Islam. Zakat is not only to show piety to Allah SWT but can also be a solution to socio-economic problems such as reducing poverty. The potential of zakat and waqf in Indonesia is growing rapidly. Recently, the government and the public have paid great attention to zakat management institutions. Optimization of both can support sustainable programs and alleviate poverty in development, health and education of the people. This is with the issuance of regulations regarding zakat management institutions to make financial reports where the financial statements must be audited. The aims of audit sharia at zakat in National Amil Zakat Agency (BAZNAS) Tulungagung. The method used in this study is a descriptive qualitative approach. Sources of data used are interviews, observation and documentation. The results showed that $B A Z N A S$ Tulungagung Regency in its financial statements had conducted a financial audit as well as a sharia audit. The financial reports of $B A Z N A S$ Tulungagung Regency since 2019 bave been audited by the Public Accounting Firm of Supribadi and Partners in Malang as well as by the Regional Office of the Ministry of Religion of East Java Province for Islamic Information, Zakat and Waqf.

Keywords: Accountability, Alms, Infaq, Sharia Audit, Zakat.

Abstrak: Zakat adalah salah satu dari Rukun Islam. Kewajiban untuk membayar zakat bukan hanya untuk menunjukkan ketakwaan kepada Allah SWT akan tetapi juga dapat menjadi solusi untuk masalah sosial ekonomi seperti mengurangi kemiskinan. Potensi zakat dan wakaf di Indonesia berkembang pesat. Pemerintah dan masyarakat, dewasa ini telah mmberikan perhatian tinggi atas lembaga pengelola zakat. Pengelolaan yang optimal dari kedua pihak didukung dengan diselenggarakan program pembangunan di bidang kesehatan, pengentasaan kemiskinan, kelaparan, kesehatan dan pelayanan pendidikan umat. Setelah ditetapkan aturan kewajiban bagi lembaga pengelola zakat menyusun laporan keuangan dan selanjutnya agar diaudit. Tujuan penelitian ini untuk mendeskripsikan tentang implementasi penerapan audit syariah pada Badan Amil Zakat Nasional (BAZNAS) Kabupaten Tulungagung. Metode penelitian menggunakan pendekatan kualitatif deskriptif. Pengumpulan data yang digunakan adalah wawancara, observasi dan dokumentasi. Hasil penelitian menyatakan jika BAZNAS Kabupaten Tulungagung laporan keuanganya telah diaudit. Tahun 2019 laporan keuangan telah diaudit oleh Kantor Akuntan Publik Suprihadi \& Rekan dan diaudit oleh Kantor Wilayah Kementerian Agama Provinsi Jawa Timur Bidang Penerangan Agama Islam, Zakat dan Wakaf. 
Kata kunci: Akuntabilitas, Audit Syariah, Infaq, Sedekah, Zakat.

\section{PENDAHULUAN}

Kewajiban membayar zakat terungkap pada 623 sebelum masehi atau periode ke-2 setelah Rasul pindah atau hijrah dari Mekah ke Madinah. Sebelumnya zakat tidak pernah diwajibkan sehingga orang melakukannya secara sukarela tanpa perincian dan pertanggungjawaban (Qardawi, 2004). Zakat adalah salah satu bagian dari rukun Islam ketiga. Arti dari zakat sebagai pembersih karena zakat dapat membersihkan harta dan jiwa para muzakki (orang yang berkewajiban zakat). Membayar zakat tidak hanya untuk menunjukkan ketakwaan seseorang kepada yang Khaliq, tetapi juga dapat menjadi solusi untuk masalah sosial ekonomi seperti mengurangi kemiskinan.

Pengelolaan zakat secara maksimal sebagai sumber daya yang sangat potensial dan dapat membantu kesejahteraan kehidupan bermasyarakat. Terdapat beberapa poin yang menjadi penyebab utama terkendalanya penyaluran zakat di Indonesia. Pertama, minimnya pendidikan keagamaan umat Islam di Indonesia, masyarakat umumnya masih beranggapan bahwa menunaikan zakat, infaq, maupun sedekah sebagai kebaikan bukan sebagai suatu kewajiaban. Kendala yang selanjutnya terletak pada lembaga atau badan yang mengelola penyaluran zakat. Kesenjangan besar terjadi antara potensi dan realisasi zakat merupakan suatu keadaan yang harus dihadapi oleh Lembaga Zakat.

Undang-undang tentang zakat pertama kali ditetapkan oleh pemerintah tahun 1999, yaitu undang-undang nomor 38 tentang pengelolaan zakat. Pada undang-undang tersebut mejelaskan jika pemerintah menetapkan dua lembaga pengelolaan zakat terdiri dari BAZNAS dan Lembaga Amil
Zakat (LAZ). Kedua lembaga ini memiliki legalitas yang disahkan oleh pemerintah.

Pada perkembangan selanjutnya pemerintah menetapkan peraturan perundangundangan yang baru yaitu UU Nomor 23 tahun 2011 tentang Pengelolaan Zakat sebagai pengganti UU nomor 23 tahun 1999. Undangundang terbaru mewajibkan jika lembaga pengelola zakat agar laporan keuangannya dilaksanakan audit. Audit yang dijalankan adalah audit atas laporan keuangan secara syariah.

Berikut isi dari UU nomor 23 tahun 2011: 1) tata cara pengangkatan dan pemberhentian anggota BAZNAS; 2) tatakerja sekretariat BAZNAS; 3) tata kerja BAZNAS provinsi/kabupaten/kota; 4) persyaratan organisasi, mekanisme perizinan, pembentukan perwakilan, pelaporan dan pertanggungjawaban LAZ; 5)lingkup kewenangan pengumpulan zakat BAZNAS; 6) pelaporan BAZNAS provinsi, kapupaten dan kota; 7) pembiayaan BAZNAS dan penggunaan hak amil; 8) sanksi administratif.

Pelaksanaan audit merupakan proses penyampaian informasi kepada pihak yang ada di luar lembaga agar mengahasilkan informasi yang lebih transparan. Tujuan dari transaparansi agar para donatur dan masyarakat memiliki tingkat kepercayaan yang tinggi atas dana yang disumbangkan ke Lembaga Zakat.

BAZNAS merupakan lembaga pengelolaan zakat yang ada di wilayah Kabupaten Tulungagung. BAZNAS sebagai lembaga pengelola zakat yang resmi dari pemerintah memiliki tugas untuk menghimpun dan menyalurkan dana Zakat, 
Infaq dan Sedekah (ZIS). Penyaluran ZIS berdasarkan atas program yang telah dituangkan dalam Rencana Kerja Anggaran Tahunan (RAT). Salah satu program yang dijalankan adalah PK-5. Program ini membantu menyalurkan pinjaman tanpa adanya bunga dan agunan, dana ini disalurkan pada pedagang yang pada level menengah ke bawah. Selain itu dana ZIS diberikan untuk memajukan pendidikan, dakwah dan kesehatan untuk masyarakat di Kaupaten Tulungagung.

Berikut merupakan daftar laporan aktivitas pada lembaga BAZNAS Kabupaten Tulungagung:

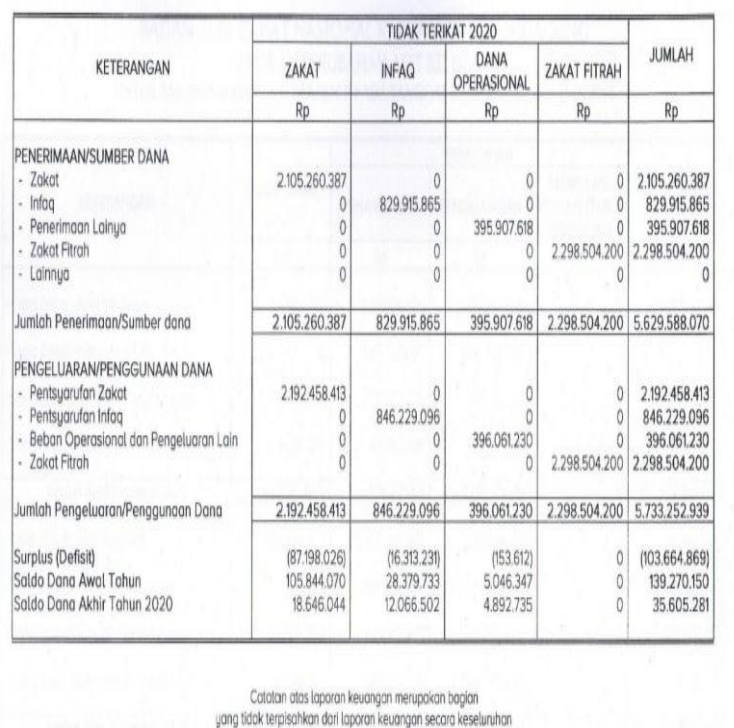

Gambar 1

Laporan Aktivitas BAZNAS Tulungagung

Sumber: BAZNAS, 2021

Audit syariah secara teori menjelaskan tentang proses yang terstruktur dalam mendapatkan bukti yang relevan dan cukup guna menghasilkan pendapat tentang personel, proses penyusunan laporan keuangan dan yang tidaktermasuk dalam laporan keuangan yang sesuai dengan prinsip diterimakan secara umum dan pelaporannya diperuntukkan bagi pengguna (Kasim, 2013: 6). Cakupan audit syariah lebih luas apabila dibandingkandengan audit konvensional. Selain harus disesuaikan dnegan prinsip syariah, audit syariah untuk pertanggungjawabannya juga kepada Allah SWT.

Pelaksanaan audit syariah berpedoman pada Pernyataan Standar Akuntansi Keuangan (PSAK) Nomor 109 tenteng Zakat, Infak dan Sedekah. Berdasarkan PSAK 109 laporan keuangan amil meliputi laporan posisi keuangan (Neraca), laporan perubahan dana, laporan aset kelolaan, laporan arus kas dan catatan atas laporan keunagan. Neraca, dan laporan penerimaan. Pengeluaran dan perubahan organisasi zakat, infak dan sedekah merupakan penggabungan atas dana sedekah dan zakat, sedangkan untuk laporan perubahan posisi keuangan secara keseluruhan digambarkan pada kondisi keuangan organisassi pengelola zakat. isi laporan berupa kebijakan akuntansi dan prosedur yang dijalankan sehingga menghasilkan angka untuk selanjutnya disajikan pada laporan keuangan tersebut.

Penelitian ini berfokus pada pelaksanaan audit syariah. Pertanyaan penelitian: 1) Apakah penyusunan laporan keuangan BAZNAS telah sesuai dengan PSAK 109 tentang ZIS Kabupaten Tulungagung?; 2) Bagaiaman penerapan audit Syariah atas laporan keuangan BAZNAS Kabupaten Tulungagung?

\section{METODE PENELITIAN}

Pendekatan penelitian ini menggunakan pendekatan kualitatif deskrptif. Lokasi penelitian diBAZNAS Kabupaten Tulungagung Jl. Mayor Sujadi Timur No 172. KabupatenTulungagung(Baznastulungagung.or .id/profil. Diakses tanggal 1 Oktober 2021). Teknik analisis menggunakan observasi dengan melakukan pengamatan di lokasi penelitian, wawancara dengan bagian akuntansi, pimpinan dan auditor internal di BAZNAS, dokumen yang berkaitan dengan audit laporan keuangan. Teknik analisis yang 
dipergunakan adalah analisis kualitatif. Digambarkan sebagai berikut:

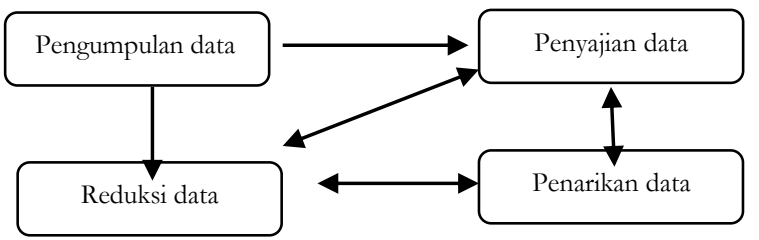

Gambar 2

Analisis interaktif Miles dan Hubberman

Sumber: Olahan Penulis

Gambar diatas menjelaskan analisis interaktif. Analisis data dilakukan dengan pengumpulan data, penyajian data, penarikan kesimpulan dan reduksi data.

\section{HASIL PENELITIAN DAN PEM B A H ASA N}

Pengakuan dan pengukuran perlakuan akuntansi pada BAZNAS Kabupaten Tulungagung telah menghasilkan laporan keuanagan telah sesuai dengan standar akuntansi zakat yang berlaku. Penyajian laporan keuangan dan pengungkapannya belum sepenuhnya sesuai dengan PSAK 109 tentang ZIS. Penerapan kegiatan Audit syariah dilaksanakan secara komprehensif, transparan, akuntabel dan akurat.

Pedoman audit syariah ditetapkan oleh Keputusan Menteri Agama Republik Indonesia yaitu penetapan tahapan dari audit syariah untuk pengelolaan zakat, infaq, sedekah, dan dana sosial keagamaan lainnya. Tahapan yang dimaksud meliputi: tahapan perencanaan, pelaksanaan dan pelaporan pada tingkatan BAZNAS propinsi, kabupaten,kota. Pada prakteknya BAZNAS Kabupaten Tulungagung telah melaksanakan tiga level audit laporan atas keuangan yaitu audit internal, audit eksternal dan audit syariah.

\section{Audit Internal}

Pengertian audit internal menurut pendapat Mulyadi: aktivitas yang bebas dalam suatu organisasi pelaksanaan kegiatan dengan memeriksa keuangan, akuntansi dan aktivitas lainnya guna memberikan jasa layanan pada pihak manajemen sebagai perwujudan tanggungjawab (Mulyadi, 2014). Selanjutnya pengertian audit internal menurut Tugiman: internal audit sebagai fungsi pemeriksaan yang amndiri dalam organisasi guna menguji dan mengevalausi aktivitas organisasi tersebut (Tugiman, 2011).

Informasi yang disajikan pada pelaporan keuangan merupakan tanggungjawab dari pihak manajemen. Laporan keuangan harus disajikan dengan jujur dan sesuai dengan kondisi yang ada.

Audit internal dibentuk dilingkungan internal organisasi yang memiliki peran melaksanakan pemeriksaan dan evaluasi atas kegiatan internal organisasi sebagai bentuk dukungan atas organisasi tersebut. Lembaga yang berkeinginan memiliki internal auditor hendaknya memberikan dukungan penuh misalnya dengan penempatan posisi secara independen, memberikan bonus dan insentif, gaji atau upah, meluangkan waktu untuk mendengarkan dan mempelajari penyampain laporan dari internal auditor.

Tujuan audit internal adalah membantu manajemen beserta jajarannya di dalam pencapaian pelaksanaan tugas dan kewajiban, mengatur secara otomatis serta mengevaluasi pengendalian internal lembaga. Auditor harus memastikan seluruh kegiatan lembaga apakah telah dijalankan sesuai dengan tujuan dari pendirian lembaga tersebut yang dalam hal ini adalah praktik akuntansinya. Pelaksanaan praktik akuntansi telah dilaksanakan sesuai dengan akuntansi yang diterimakan secara umum

Internal audit jika berjalan efektif, akan berdampak pada pengurangan praktik-praktik 
akuntansi yang tidak sehat. Internal audit tata kelola kelembagaannya jika dijalankan dengan efektif akan menunjukkan jika lembaga tersebut dalam kondisi sehat.

Pengendalian internal kelembagaan apakah juga telah dijalankan sebagaimana mestinya. Audit internal yang efektif dapat ditandai dengan jalannya lembaga yang selaras dengan tujuan perusahaan. Nilai tambah bagi kinerja lembaga meningkat, dan posisi keuangan tetap stabil dari waktu ke waktu.

Audit internal dalam pengelolaan zakat merupakan suatu aktivitas yang bertujuan untuk mengevaluasi, memastikan dan meningkatkan efektifitas pengelolaan resiko dan tata kelola lembaga zakat agar terkendali dengan baik. Auditor internal lembaga pengelola zakat harus mengetahui terkait operasi dan resiko yang dapat terjadi di lembaga.

BAZNAS Kabupaten Tulungaung menetapkan kriteria asnaf penerima dana sebagai berikut:

\section{Tabel 1}

Penerima Dana dari BAZNAS Kabupaten Tulungagung

\begin{tabular}{|c|c|c|}
\hline No & Asnaf & an Dana \\
\hline 1 & $\begin{array}{l}\text { Fakir } \\
\text { Miskin }\end{array}$ & $\begin{array}{l}\text { Fakir dan Miskin } \\
\text { dijadikan satu besarannya } \\
\text { mengacu data dari BPS }\end{array}$ \\
\hline 2 & Amil & $\begin{array}{l}\text { besarannya } 2,5 \% \text { dari } \\
\text { dana yang diterima dalam } \\
\text { satu tahun. Selanjutnya } \\
\text { dana tersebut disalurkan } \\
\text { ke UPZ }\end{array}$ \\
\hline 3 & $u_{a}$ & $\begin{array}{lr}\text { Dana } & \text { diberikan } \\
\text { berdasarkan } & \text { penetapan } \\
\text { dari RKAT. Namun dana } \\
\text { ini tidak } & \text { tersalurkan } \\
\text { dikarenakan } & \text { jumlah } \\
\text { mualaf di } & \text { Kabupaten } \\
\text { Tulungaung } & \text { sangat } \\
\text { rendah } & \\
\end{array}$ \\
\hline 4 & iqqop & Belum \\
\hline
\end{tabular}

\begin{tabular}{|l|l|l|}
\hline & & direalisasikan \\
\hline 5 & Gharim & $\begin{array}{l}\text { Dibuktikan dengan } \\
\text { memiliki rinjaman. } \\
\text { Pengajuan dengan } \\
\text { proposal }\end{array}$ \\
\hline 6 & Fi & $\begin{array}{l}\text { Mengajukan proposal ke } \\
\text { SAZNAS dengan } \\
\text { ketentuan selama 3 tahun } \\
\text { terakhir belum pernah } \\
\text { menerima bantuan dari } \\
\text { BAZNAS }\end{array}$ \\
\hline 7 & $\begin{array}{l}\text { Ibnu } \\
\text { Sabil }\end{array}$ & jumlahnya minim. \\
\hline
\end{tabular}

Sumber: data diolah Peneliti, 2021

Auditor internal di lembaga zakat setidaknya harus memonitor aktivitas secara rutin dan mengevaluasi kepatuhan lembaga zakat terhadap kebijakan pada lembaga. Auditor internal di lembaga zakat diharuskan untuk melaporkan hasil asesmen internal kepada komite audit atau kepada lembaga yang mengatur pengelolaan zakat secara berkala. BAZNAS Kabupaten Tulungagung telah menerapkan audit internal yang diaudit oleh Satuan Audit Internal (SAI). Dengan diterapkannya audit internal lembaga zakat dapat mempertahankan efektifitas lembaga.

\section{Audit Eksternal}

Perbedaanya auditor internal dengan eksternal audit adalah jika audit internal melaksanakan review yang berkelanjutan pada kegiatan lembaga, sedangkan auditor eksternal melaksanakan audit secara rutin dalam tahunan atau periodik. Tujuan dari melakukan audit eksternal yaitu untuk mengetahui apakah laporan keuangan lembaga menyajikan laporan yang nyata terhadap finansial lembaga yang terkait. Audit ekternal dilakukan untuk mendorong transparasi lembaga pengelola zakat.

Perlakuan akuntansi untuk aktivitas zakat, Infaq dan Sedekah (ZIS) untuk 
BAZNAS Kabupaten Tulungagung diterimakan ketika transaksi tersebut masuk dan transaksi keluar dicatatkan pada saat dana disalurkan menurut program yang telah disusun dalam Rapat Kerja Anggaran Tahunan (RKAT). Pada saat penerimaan dana ZIS kasir memasukkan nominal setoran sekaligus data muzakki mempergunakan aplikasi SIMBA. Bukti setor dicetak rangkap dua, satu diberikan pada Mustahiq dan satu lagi untuk arsip.

Selain menggunakan aplikasi SIMBA, pihak kasir melakukan rekap secara manual di jurnal pelaporan. Ketika pendistribusian dan penyaluran dana ZIS pada para asnaf, kasir mencatat transaksi tersebut secara manual dan aplikasi SIMBA setiap sepuluh hari pasca jurnal pelaporan disetor ke bagian perencanaan dan pelaporan.

Bagian keuangan menyusun laporan bulanan dan menyusun rincian penerimaan dan pendistribusian dana untuk tiga bulan yang selanjutnya disalurkan ke UPZ. Laporan keuangan bulanan digabung menjadi satu untuk disajikan sebagai laporan tahunan dan selanjutnya untuk dilakukan audit oleh audit independen yaitu dari Kantor Akuntan Publik.

Sejak tahun 2018, BAZNAS tahun telah melaksanakan audit oleh auditor indepen dengan menggunakan jasa akuntan yang tergabung dalam KAP Suprihadi dan Rekan yang beralamatkan di JL. Bunga Andong Selatan Kav. 26 Perum Simpang Soekarno Hatta, Lowokwaru Kota Malang. Hasil audit oleh KAP Suprihadi \&Rekan.

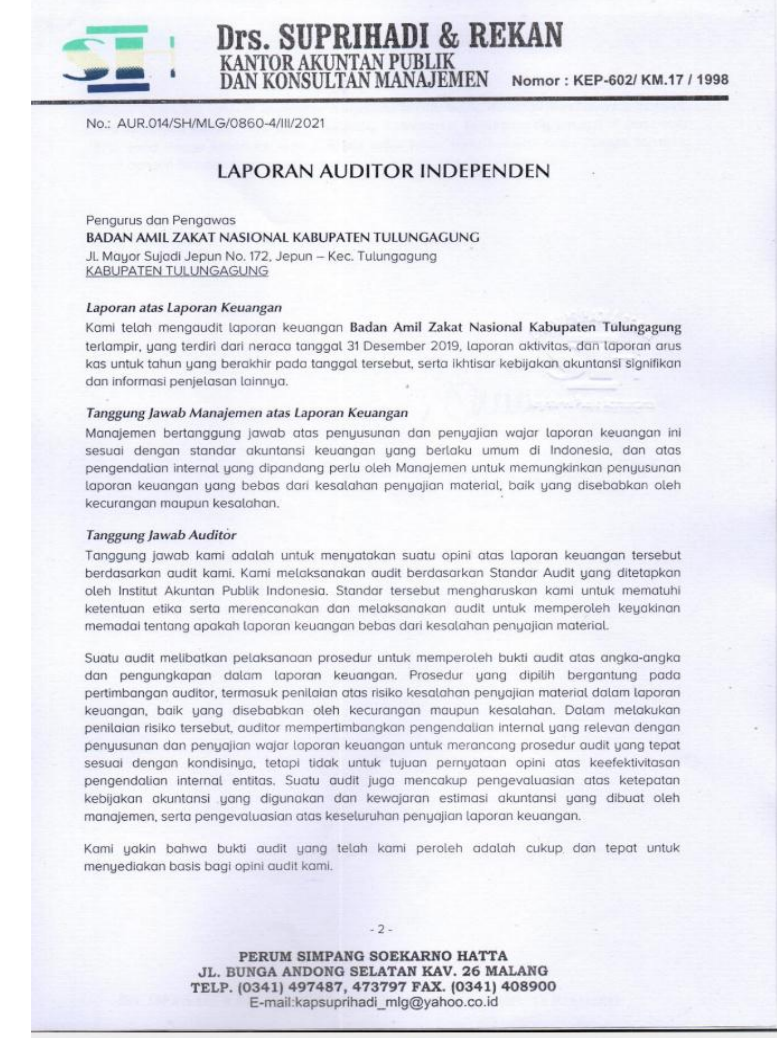

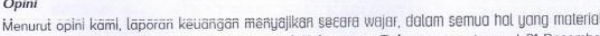
posisis keuongon Badan A mil Zakat Nasional Kabupaten Tulungagung tanggal 31 Desember sesuol dengan Standar Akuntansi Keuangan yang berlaku umum di Indonesia.

\section{Gambar 3: Laporan auditor dari KAP} Suprihadi\& Rekan

Sumber: BAZNAS Kabupaten Tulungagung

Berdasarkan hasil audit menjelaskan jika laporan keuangan yang dikelola oleh BAZNAS opini wajar, yang artinya bahwa laporan keuangan yang disajikan memiliki pengertian bahwa laporan keuangan tersebut bebas dari keraguan dan bebas dari ketidakjujuran serta informasi yang disajikan telah lengkap.

\section{Audit Syariah}

Kebutuhan audit syariah pada awalnya untuk lembaga keuangan syariah yang pertama kali berkembang pesat di zaman modern dibandingkan dengan lembaga zakat. Pada tahun 2011 Dubai Islamic Bank menyatakan bahwa bank syariah dan industri keuangan syariah adalah lembaga keuangan dengan 
pertumbuhan tercepat di sektor ekonomi dunia (Jacob, 2013).

Meskipun jika dibandingkan dengan bank konvensional sistem keuangan syariah masih dalam tahap pengembangan. Ada beberapa kendala utama audit syariah di Indonesia salah satunya kompetensi sumber daya manusia.

Audit syariah tidak jauh berbeda dengan audit konvensional. Perbedaannya terletak pada tambahan obyek audit yang berhubungan dengan syariah.

\section{Tabel 2}

Perbedaan Audit Syariah dan Audit Konvensional.

\begin{tabular}{|l|l|l|}
\hline Uraian & \multicolumn{1}{|c|}{$\begin{array}{c}\text { Audit } \\
\text { Syariah }\end{array}$} & $\begin{array}{c}\text { Audit } \\
\text { konvensional }\end{array}$ \\
\hline Obyek & $\begin{array}{l}\text { Lembaga } \\
\text { Keuangan } \\
\text { baik bank } \\
\text { dan non } \\
\text { bank yang } \\
\text { berbasis } \\
\text { syariah }\end{array}$ & $\begin{array}{l}\text { Lembaga } \\
\text { keuangan bank } \\
\text { dan non bank } \\
\text { yang berbasis } \\
\text { konvensional }\end{array}$ \\
\hline Pengawas & $\begin{array}{l}\text { DPS } \\
\text { (Dewan } \\
\text { Pengawas } \\
\text { Syariah) }\end{array}$ & $\begin{array}{l}\text { Tidak adanya } \\
\text { DPS }\end{array}$ \\
\hline Auditor & $\begin{array}{l}\text { Bergelar } \\
\text { SAS } \\
\text { (Sertifikat } \\
\text { Akuntan } \\
\text { Syariah) }\end{array}$ & $\begin{array}{l}\text { Auditor Umum } \\
\text { AAOIFI } \\
\text { aturan } \\
\text { Syariah } \\
\text { kepatuhan } \\
\text { dengan uji } \\
\text { Aerkaitan } \\
\text { atas laporan }\end{array}$ \\
\hline Standar & Wajar atau tidak \\
\hline Opini & $\begin{array}{l}\text { IAI } \\
\text { angan }\end{array}$ \\
\hline
\end{tabular}

Berdasarkan Peraturan Pemerintah no. 14 tahun 2014, lembaga zakat syariah diaudit oleh kementerian agama. Audit syariah yang dilaksanakan untuk menguji kepatuhanterhadap aturan dan prinsip syariah yang diterimakan secara umum. Standar yang dipergunakan adalah AAOIFI dan auditornya bersertifikat SAS atau setidaknya telah mengikuti seminar dan berbagai pelatihan terkait audit lembaga keuangan syariah. Selain itu memiliki kepakaran terkait fatwa yang dikeluarkan oleh DSN MUI, Undnag-undang, Perarturan Pemerintah, Keputusan Menteri Agama RI, dan terakhir tentang Peraturan Direktur Jenderal dan Peraturan BAZNAS. Semakin berkembang pesat lembaga keuangan syariah maka persaingan sebagai auditor syariah meningkat.

Beberapa hal yang menjadi perhatikan dalam audit syariah di lembaga zakat adalah memastikan pengumpulan zakat, mengelolaan dan pendistribusian zakat sesuai dengan prinsip-prinsip syariah. Dalam instrumen pengumpulan meliputi tentang muzakki penerimaan kertas pembayaran, penerimaan lembaga zakat halal (harta atau dana yang disahkan) atau bukan dari cucian uang. Hal ini juga memastikan penggunaan hak amil (dana operasional untuk lembaga zakat) telah dilakukan sesuai dengan prinsip-prinsip syariah dan lembaga zakat tidak mengambil lebih dari $1 / 8$ atau sekitar $12.5 \%$ dari total zakat (1/8 adalah bagian kewajaran untuk dana amil). Instrumen pendistribusian termasuk lembaga zakat memastikan penerima zakat adalah orang yang tepat berdasarkan kriteria Al-Qur'an dan memastikan dana zakat tidak berada di rekening bank lebih dari 1 tahun.

Selain itu, sistem keuangan berbasis syariah melarang bunga bank karena termasuk riba. Riba adalah salah satu dosa besar dalam Islam. BAZNAS Kabupaten Tulungagung memiliki rekening bank konvensional. Alasan 
kepemilikan rekening tersebut adalah untuk simpanan yang sifatnya sementara, hal ini dikarenakan Muzakki berasal dari pegawai pemerintah dilingkungan Kabupaten Tulungagung, yang rekening gajinya dibank konvensional. Transaksi lainnya tetap menggunakan bank syariah.. Apalagi komisaris utama berpendapat bahwa lembaga zakat masih memiliki rekening bank konvensional tidak menjadi instrumen utama untuk audit syariah. BAZNAS Kabupaten Tulungagung laporan keuangan telah diaudit oleh Kementerian Agaman Propinsi Jawa Timur, Bidang Penerangan Agama Islam, Zakat dan Wakaf.

\section{KESIMPULAN}

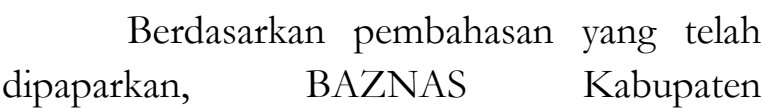
Tulungagung telah menerapkan tiga audit pada laporan keuangannya yaitu audit internal oleh Satuan Audit Internal (SAI), audit eksternal oleh KAP Suprihadi\&Rekan yang berlokasi di Kota Malang dan telah dilaksanakan audit syariah oleh Kanwil Kementerian Agama Provinsi Jawa Timur Bidang Penerangan Agama Islam, Zakat dan Wakaf.

BAZNAS Kabupaten Tulungagung dengan hasil audit, menunjukkan jika BAZNAS Kabupaten Tulungagung menunjukkan bahwa sebagai lembaga pengelola keuangan yang dihimpun dari masyarakat mampu memenuhi tanggungjawab sebagai organisasi pengelola zakat. Hasil audit dari pihak eksternal dan independen, laporan keuangannya telah sesuai dengan prinsip syariah dan dapat masyarakat dapat menaruh kepercayaannya. Meskipun begitu, masih terdapat beberapa poin yang belum sesuai dengan audit syariah BAZNAS Kabupaten Tulungagung masih menggunakan rekening yang berbasis konvensional. Hal ini tidak menjadi instrumen utama untuk audit syariah, namun akan lebih baik jika dihindari supaya tidak menimbulkan adanya riba maupun gharar.

\section{DAFTAR KEPUSTAKAAN}

Ardi, Muhammad. Rahayu, Rusti. (2018). Pengaruh Penerapan Audit Syariah Pada Peningkatan Kepercayaan Publik (Studi Kasus di Lembaga Amil Zakat). Iqtishaduna: Jurnal Ekonomi dan Keuangan Islam. 4 (2).

As-salafiyah, Aisyah. Rusydiana, Aam slamet. (2020). Sharia Audit Problems In Zakat Institutions: Evidence From Indonesia. Jurnal Ekonomi dan Bisnis Islam (Journal of Islamic Economics and Business). 6 (2).

Badan Amil Zakat Nasional. (2021). Profil

$B A Z N A S$. Diakses pada 1 Oktober 2021 dari halaman web: https://baznas.go.id/profil.

Harahap, Sofyan Syafri dkk. (1994). Auditing Kontemporer, Jakarta: Erlangga.

Jacob. Denis. 2013. Analisis Laporan Keuangan dengan Menggunakan Metode CAMEL untuk Menilai Tingkat Kesehatan Perbankan. Jurnal Ekonomi dan Bisnis. Jakarta.

Megawati, Devi. (2018). Implementation of Auditing in Zakat Institutions: Case studies of BAZNAS Riau and Pekanbaru. Tarkia Islamic Finance and Business Review. 12 (2

Mulyadi. 2014. Auditing edisi Keenam. Jakarta. Salemba Empat

Sugiyono. 2014. Metode Penelitian Kuantitatif, Kualitatif dan R\&DD. Bandung Alfabeta.

Sukrisno Agoes. (2012). Auditing; Petunjuk Praktis Pemeriksaaan Akuntan oleh Akuntan Publik. Jakarta: Salemba Empat.

Susilowati, Lantip. Khofifa, Fatimatul.

(2020). Kesesuaian Akuntansi Zakat, Infaq dan Sedekah dengan PSAK 109 BAZNAS Kabupaten Tulungagung. Jurnal Akuntansi Syariah. 4(2).

Tugiman. Hiro. 2011. Pandangan Baru Internal Auditing. Yogyakarta. Karnisius 
Undang-Undang Republik Indonesia No. 23

Tahun 2011 Tentang Pengelolaan

Zakat. 